\title{
Mitochondrial Impairment in Oligodendroglial Cells Induces Cytokine Expression and Signaling
}

Miriam Scheld ${ }^{1}$, Athanassios Fragoulis ${ }^{2}$, Stella Nyamoya ${ }^{1,3}$, Adib Zendedel $^{1}$, Bernd Denecke ${ }^{4}$, Barbara Krauspe ${ }^{5}$, Nico Teske ${ }^{3}$, Markus Kipp ${ }^{6}$, Cordian Beyer ${ }^{1}$, Tim Clarner ${ }^{1}$

${ }^{1}$ Institute of Neuroanatomy, Faculty of Medicine, RWTH Aachen University, 52074 Aachen, Germany, mscheld@ukaachen.de

${ }^{2}$ Department of Anatomy and Cell Biology, Faculty of Medicine,

RWTH Aachen University, 52074 Aachen, Germany

${ }^{3}$ Department of Anatomy II, Ludwig-Maximilians-University of Munich, 80336 Munich, Germany

${ }^{4}$ IZKF Genomics Facility, Interdisciplinary Center for Clinical Research, RWTH Aachen University, 52074 Aachen, Germany

${ }^{5}$ Clinic for gynaecology and obstetrics, Faculty of Medicine, RWTH Aachen University, 52074 Aachen, Germany

${ }^{6}$ Institute of Anatomy, University of Rostock, 18057 Rostock, Germany

\section{Abstract}

Widespread inflammatory lesions within the central nervous system grey and white matter are major hallmarks of multiple sclerosis. The development of full-blown demyelinating multiple sclerosis lesions might be preceded by preactive lesions which are characterized by focal microglia activation in close spatial relation to apoptotic oligodendrocytes. In this study, we investigated the expression of signaling molecules of oligodendrocytes that might be involved in initial microglia activation during preactive lesion formation. Sodium azide was used to trigger mitochondrial impairment and cellular stress in oligodendroglial cells in vitro. Among various chemokines and cytokines, IL6 was identified as a possible oligodendroglial cell-derived signaling molecule in response to cellular stress. Relevance of this finding for lesion development was further explored in the cuprizone model by applying shortterm cuprizone feeding $(2-4 d)$ on male C57BL/6 mice and subsequent analysis of gene expression, in situ hybridization and histology. Additionally, we analyzed the possible signaling of stressed oligodendroglial cells in vitro as well as in the cuprizone mouse model. In vitro, conditioned medium of stressed oligodendroglial cells triggered the activation of microglia cells. In cuprizone-fed animals, IL6 expression in oligodendrocytes was found in close vicinity of activated microglia cells. Taken together, our data supports the view that stressed oligodendrocytes have the potential to activate microglia cells through a specific cocktail of chemokines and cytokines among IL6. IL6. Further studies will have to identify the temporal activation pattern of these signaling molecules, their cellular sources and impact on neuroinflammation.

\section{Introduction}

Stressed oligodendrocytes in close proximity to foamy macrophages and clustered microglia expressing HLADR are found widespread within the normal appearing white matter of multiple sclerosis (MS) patients (De 
Groot, Bergers et al. 2001, Zeis, Probst et al. 2009). These preactive lesions are thought to precede the development of full-blown demyelinating MS lesions (De Groot, Bergers et al. 2001, Wuerfel, Bellmann-Strobl et al. 2004, van der Valk and Amor 2009). Therefore, it seems reasonable to assume that the initial microglia activation and clustering as observed in preactive lesions might be triggered by oligodendrocyte-derived signaling molecules. It has been shown that oligodendrocytes are able to secrete a variety of signaling molecules such as chemokines, cytokines and other regulatory proteins which are known to be involved in the regulation of immunological processes (Cannella and Raine 2004, Balabanov, Strand et al. 2007, Kummer, Broekhuizen et al. 2007, Okamura, Lebkowski et al. 2007, Tzartos, Friese et al. 2008, Merabova, Kaminski et al. 2012, Ramesh, Benge et al. 2012, Moyon, Dubessy et al. 2015). For example, IFN $\gamma$-treated primary rat oligodendrocytes significantly induced the expression of the chemokines CXCL10, CCL2, CCL3, and CCL5 (Balabanov, Strand et al. 2007). Furthermore, the cytokines IL6 and IL8 and the chemokine CCL2 were significantly induced in the human oligodendrocyte cell line MO3.13 when confronted with Borrelia burgdorferi. Exposure to the same bacteria caused the induction of IL8 and CCL2 in a dose-dependent manner in primary human oligodendrocytes (Ramesh, Benge et al. 2012).

So far, it is not completely understood which processes trigger oligodendrocyte stress and subsequent expression of signaling molecules. One factor leading to oligodendrocyte stress, impaired mitochondrial functions and increased levels of reactive oxygen species (Wang, Wu et al. 2013) might be the accumulation of mutations within the mitochondrial genome. It is known that the mtDNA is prone to mutations with a mutation rate that is about 10-fold higher than chromosomal DNA (Linnane, Marzuki et al. 1989). In comparison to other cell populations, oligodendrocytes have a reduced capacity to repair their mtDNA, possibly due to particularities in the expression of factors involved in DNA repairing mechanisms (Hollensworth, Shen et al. 2000). With respect to demyelination and oligodendrocyte pathology, both mutations in mitochondrial genes as well as oxidative stress play a role in lesion formation and disease progression in MS and MS-related animal models (Mahad, Lassmann et al. 2008, Mao and Reddy 2010, Su, Bourdette et al. 2013, Draheim, Liessem et al. 2016).

As the sentinels and injury sensors of the central nervous system (CNS), microglia can be activated by many kinds of mechanical injury and pathological disturbances within the CNS (Perry, Andersson et al. 1993, Gehrmann, Matsumoto et al. 1995). In MS, the magnitude of myelin loss during demyelinating events positively correlates with the number of activated microglia cells (Clarner, Diederichs et al. 2012). Furthermore, microgliosis can be induced by leukocyte infiltration into the CNS (Scheld, Ruther et al. 2016, Ruther, Scheld et al. 2017). However, the listed factors are rather unlikely to contribute to the activation of microglia cells during the formation of preactive lesions, since the affected brain regions lack any signs of demyelination, leukocyte infiltration, astrogliosis or inciting agents such as viral or bacterial antigens (Gay, Drye et al. 1997, De Groot, Bergers et al. 2001, Barnett and Prineas 2004, Marik, Felts et al. 2007, van der Valk and Amor 2009). A growing body of evidence suggests that stressed oligodendrocytes might be active contributors to MS lesion formation by initiating microglia reactivity. Barnett and Prineas have reported areas with an extensive oligodendrocyte apoptosis and concomitant microgliosis in the absence of infiltrating immune cells in the normal appearing white matter of MS patients, thus indicating that oligodendrocyte loss precedes inflammatory demyelination (Barnett and Prineas 2004).

In this study, we use the oligodendroglial cell line OLN93 to screen for oligodendrocyte-derived chemokines and cytokines that are potentially able to activate microglia cells. Subsequent culture experiments with the microglia cell line BV2 show that IL6, which is robustly expressed by stressed oligodendroglial cells, is a constituent of a 
cocktail of secreted proteins, which are responsible for microglia activation. Finally, IL6 expression was explored in the cuprizone model, which recapitulates distinct but important aspects of early MS lesion formation.

\section{Materials and methods}

\section{Cell culture}

Cells of the oligodendroglial linage cell line OLN93 were received from Dr C. Richter-Landsberg (RRID: CVCL_5850; Oldenburg, Germany) and chosen as a model system because of strong similarities to primary oligodendrocytes regarding morphology and gene expression (Richter-Landsberg and Heinrich 1996). BV2 cell line was cultured according to Dr. E. Blasi (RRID: CVCL_0182; Modena, Italy) and chosen as a model system because of its suitability to study molecular mechanisms that control induction and expression of biological activities in microglia (Blasi, Barluzzi et al. 1990). Cell lines were not authenticated prior to experiments. None of the cell lines used in these experiments is listed as a commonly misidentified cell line by the International Cell Line Authentication Committee. OLN93 oligodendroglial cell line and BV2 microglial cell lines were maintained in Dulbecco's Modified Eagle Medium supplemented with 5\% (OLN93) and 10\% (BV2) heatinactivated fetal bovine serum, penicillin $\mathrm{G}(10,000$ units $/ \mathrm{mL})$, and streptomycin $(10,000 \mu \mathrm{g} / \mathrm{mL})$. For experiments, cells were seeded into 6-well dishes, $10 \mathrm{~cm}$ culture dishes or $75 \mathrm{~cm}^{2}$ flasks at densities of $3 \times 10^{5}$, $5 \times 10^{6}$ and $2.3 \times 10^{6}$ cells per well, respectively. Before treatment, cells were cultivated for $24 \mathrm{~h}$ in starving medium (OLN93: SATO with 1\% penicillin G/ streptomycin; BV2: DMEM supplemented with $0.5 \%$ fetal calf serum and $0.5 \%$ penicillin $\mathrm{G} /$ streptomycin). Cells were cultivated in a humidified atmosphere of $5 \% \mathrm{CO}_{2}$ at $37^{\circ} \mathrm{C}$.

\section{Oligodendroglial cell conditioned medium (OCM)}

OLN93 cells were treated with $10 \mathrm{mM}$ sodium azide (SA, Sigma Aldrich) or vehicle (UltraPure Distilled Water; Thermo Fisher Scientific) for $24 \mathrm{~h}$. After washing twice with 1x phosphate buffered saline (PBS), cells were incubated with starving medium for a $24 \mathrm{~h}$ secretion period. The medium of each treatment group was pooled, centrifuged and filtered through a $20 \mu \mathrm{m}$ cell strainer. BV2 microglia were incubated with OCM from SA treated cells (OCM-SA) for $6 \mathrm{~h}$. Oligodendroglial starving medium and OCM from vehicle groups (OCM-vehicle) served as control. OCM was additionally used for ELISA analysis. See supplementary figure A for experimental overview.

\section{Cell Viability and metabolic activity assay}

To investigate the toxic effects of the applied SA concentrations, CytoTox 96® Non-Radioactive Cytotoxicity Assay and CellTiter-Blue ${ }^{\circledR}$ Cell Viability Assay (Promega G1780, G8081) were performed according to the manufacturer's instructions. Brief, cells were seeded into an opaque-walled 96 tissue culture plate and treated with SA and vehicle for $24 \mathrm{~h}$. Treatment of cells with a lysis solution served as a negative control as all cells are dead, medium without cells served as blank. Cells were incubated with CellTiter-Blue reagent until a change of color was observed, fluorescence was measured at 560/590 nm with the Tecan infinite M200 plate reader and processed with i-control 1.10 software. Medium of cells was incubated for 30 min with CytoTox96 reagent and the reaction was stopped with stop solution. Absorbance was measured at $490 \mathrm{~nm}$ with Tecan i-control software. Data are given in \% of control fluorescence and absorbance values, respectively. No blinding was performed for the evaluation of these data. Experiments were performed with 8 biological and 2 technical replicates. 


\section{Enzyme-linked immunosorbent assay}

IL6 ELISA was conducted using cell culture supernatants of vehicle and SA-treated OLN93 cells (OCM) according to the manufacturer's protocol (Quantikine ELISA, R\&D Systems). Color development of substrate solution (stabilized hydrogen peroxide and stabilized chromogen (tetramethylbenzidine)) was monitored with a Tecan infinite M200 plate reader at $450 \mathrm{~nm}$ with a wavelength correction at $540 \mathrm{~nm}$ and processed with i-control 1.10 software. IL6 protein levels are displayed as absolute values in pg/ml. Experiments were performed with two biological and two technical replicates.

\section{Animals and cuprizone intoxication}

C57BL/6J male mice (19 $\pm 2 \mathrm{~g})$ were obtained from Janvier and housed under standard laboratory conditions in the animal facility of the Uniklinik Aachen according to the Federation of European Laboratory Animal Science Association's recommendations. Mice were maintained with food and water ad libitum in a $12 \mathrm{~h}$ light/dark cycle at controlled temperature and humidity $\left(23 \pm 2^{\circ} \mathrm{C} ; 55 \% \pm 10 \%\right.$ humidity). Experimental procedures, i.e. cuprizone feeding, were approved by the Review Board for the Care of Animal Subjects of the district government (Nordrhein-Westfalen, Germany). At noon, mice received a diet containing $0.25 \%$ cuprizone (biscyclohexanone-oxaldihydrazone, Sigma Aldrich; choice of concentration via established protocols) for up to $2 \mathrm{~d}$ mixed into a ground standard rodent chow. The control group was fed with standard rodent chow. Animals were allocated to groups applying the following procedure: Animals were distributed across cages (three animals per cage; cage area $435 \mathrm{~cm}^{2}$ ) and each group consisted of mice with comparable weight. We used cards numbered from 1 to 2 for the respective experimental group ( $1=$ control, $2=2$ days cuprizone). The number on the card randomly assigned the cages to the respective group. Re-evaluation of cDNA samples of $1-4 \mathrm{~d}$ cuprizonetreated mice were performed using previously published work from our research group (Krauspe, Dreher et al. 2015). Size of groups for each experiment is given in the appropriate figure legends and an experimental overview is shown in supplementary figure B.

\section{Tissue preparation}

Mice were anaesthetized with ketamine/xylazine $(100 \mathrm{mg} / \mathrm{kg}$ and $10 \mathrm{mg} / \mathrm{kg}$; i.p. with $100 \mu \mathrm{l} / 10 \mathrm{~g}$ body weight) and transcardially perfused with either PBS or 3.7\% formalin in PBS. Brains were removed to isolate RNA of the corpus callosum (CC) for gene expression analysis or whole brains were post-fixed in $3.7 \%$ formalin and subsequently embedded into paraffin for immunohistological analysis following established protocols (Clarner, Janssen et al. 2015).

\section{Immunohistological staining and fluorescence labeling}

For fluorescence and immunohistological analysis, $5 \mu \mathrm{m}$ thick brain slides were cut with a microtome. Rabbit anti-IL6 (Abcam ab7737), mouse anti-OLIG2 (Millipore MABN50), donkey-anti-rabbit 488 and donkey-antimouse 594 were used for fluorescence labeling (Life Technologies A21206, A21203). Signal specificity was validated by incubating slices with the respective secondary antibody without pre-incubation with the first antibody (see supplementary figure C). Furthermore, cross reactivity of secondary antibodies with each other or the false primary antibody was additionally excluded (data not shown). For chromogen double labeling, antiGFAP (Santa Cruz sc-6170), anti-IBA-1 (Millipore MABN92) and anti-APC (Millipore OP80) antibodies were visualized with a horseradish peroxidase enzyme (Vector Labs) and DAB substrate (Dako); anti-IL6 (Abcam 
ab6672) was visualized with an alkaline phosphatase (Zytomed Systems) and an AP Blue substrate that emits at $680 \mathrm{~nm}$ (Vector Laboratories).

\section{In situ hybridization}

Commercial fluorescence in situ hybridization kits (QuantiGene View RNA in situ hybridization tissue assay; Affymetrix-Panomics) were used for double labeling of formalin-fixed, paraffin-embedded tissue, following the manufacturer's recommendations. Protease digestion time was adjusted to $20 \mathrm{~min}$. Probes directed against Olig2 and $I l 6$ were purchased from Affymetrix (Affymetrix-Panomics). Confocal images were captured using the LSM710 laser-scanning microscope station (Carl Zeiss).

\section{Chemokine and cytokine array}

RNA isolation was performed with RNeasy Micro Kit (Qiagen 74004). Cells were directly lysed with RLT buffer and homogenized with Precellys homogenizer. Further isolation procedures such as washing and DNA digestion was conducted in MinElute spin columns. RNA concentration was measured with NanoDrop 2000 spectrometer. 500 ng RNA was reverse transcribed with RT $^{2}$ First Strand Kit (Qiagen 330404). Genomic DNA was eliminated and RNA reverse transcribed according to the manufacturer's instructions. Cytokine \& Chemokine RT ${ }^{2}$ Profiler PCR Array (Qiagen PARN-150ZD) was performed with RT $^{2}$ SYBR Green Mastermix and processed with Bio-Rad CFX connect cycler. PCR cycling program was composed of one $10 \min 95^{\circ} \mathrm{C}$ hot start cycle and 40 cycles of $95^{\circ} \mathrm{C} 15 \mathrm{~s}$ and $60^{\circ} \mathrm{C} 1 \mathrm{~min}$ to perform fluorescence data collection. Results were analyzed using the Data analysis center from Qiagen (https://www.qiagen.com/de/shop/genes-andpathways/data-analysis-center-overview-page). $\quad \beta$-Actin, $\quad \beta-2 \quad$ microglobulin, $\quad$ hypoxanthine phosphoribosyltransferase 1, lactate dehydrogenase A and ribosomal protein large P1 served as reference genes. Furthermore, the array contained one genomic DNA control, three replicate reverse-transcription controls to test reverse-transcription efficiency and three replicate positive PCR controls to test PCR efficiency. Experiments were performed with one biological and one technical replicate.

\section{Gene expression analysis}

RNA for array validation and microglia gene expression analysis was isolated by using peqGold TriFast (Peqlab) and reverse-transcribed in a $20 \mu \mathrm{L}$ reaction volume using a reverse-transcription kit (Thermo Fisher Scientific 28025-021). cDNA levels were then analyzed by qPCR using SensiMix SYBR® \& Fluorescein Kit (Bioline QT615-05) and Bio-Rad CFX connect cycler. The expression levels were calculated relative to the reference genes coding for glyceraldehyde 3-phosphate dehydrogenase or cyclophilin A using the $\Delta \Delta \mathrm{Ct}$ method. Primer sequences are given in table I. No blinding was performed for the evaluation of these data. Experiments were performed with at least 6 biological and 2 technical replicates if not stated otherwise. Furthermore, a gene array (Affymetrix) from the corpus callosum (CC) of control animals and animals that were fed cuprizone for $2 \mathrm{~d}$, was re-evaluated with respect to those genes identified in the OLN93 gene expression study (Krauspe, Dreher et al. 2015). 
Table I. Forward and reverse primer sequences used for qPCR analysis.

\begin{tabular}{|l|l|l|}
\hline Name & Forward sequence 5'-3' & Reverse sequence 5'-3' \\
\hline Arg1 mouse & CTCCAAGCCAAAGTCCTTAGAG & AGGAGCTGTCATTAGGGACATC \\
\hline Atf3 rat & ACTGCGTTGTCCCACTCTGT & TCATCTGAGAATGGCCGGGA \\
\hline Csf1 rat & AGCAAGGAAGCGAACGAAC & ATGTGGCTACAGTGCTCCGA \\
\hline Cyca rat & GGCAAATGCTGGACCAAACAC & TTAGAGTTGTCCACAGTCGGAGATG \\
\hline Ddit3 rat & TGTTGAAGATGAGCGGGTGG & GCTTTCAGGTGTGGTGGTGT \\
\hline Gapdh mouse & TGTGTCCGTCGTGGATCTGA & CCTGCTTCACCACCTTCTTGA \\
\hline Gdf15 rat & TCAGCTGAGGTTCCTGCTGTTC & GCTCGTCCGGGTTGAGTTG \\
\hline Il6 mouse & GATACCACTCCCAACAGACCTG & GGTACTCCAGAAGACCAGAGGA \\
\hline Il6 rat & TCTCTCCGCAAGAGACTTCCA & ATACTGGTCTGTTGTGGGTGG \\
\hline Lif rat & TTTGCCGTCTGTGCAACAAG & TGGACCACCGCACTAATGAC \\
\hline Nos2 mouse & ACATCGACCCGTCCACAGTAT & CAGAGGGGTAGGCTTGTCTC \\
\hline Spp1 rat & CCAGCCAAGGACCAACTACA & TCTCCTCTGAGCTGCCAAAC \\
\hline
\end{tabular}

201

\section{Statistical analysis}

Statistical analysis was performed using JMP10 and GraphPad Prism 5. Data are presented as arithmetic means \pm SEM. To test for equal variances, Bartlett test was performed. Data transformations via Boxcox for homoscedasticity are indicated if necessary. Shapiro-Wilk test was used to test for normal distribution. Parametric data were analyzed with one-way ANOVA followed by Tukey's post hoc test for multiple comparisons or with Student's t-test. Non-parametric data were analyzed with Kruskal-Wallis test followed by the Dunn's multiple comparison or Mann-Whitney test. $\mathrm{p}<0.05$ was considered statistically significant. The following symbols were used to indicate the level of significance: ${ }^{*} \mathrm{p}<0.05$, $* * \mathrm{p}<0.005$, ${ }^{* * *} \mathrm{p}<0.001$; ns indicates not significant. No outliers were excluded from the analyses. No sample size calculation was performed.

\section{Results}

Sodium azide induces stress in oligodendroglial cells

SA is a potent inhibitor of the mitochondrial respiratory chain and inhibits the mitochondrial complex IV which is responsible for the transfer of cytochrome c to an oxygen molecule (Bennett, Mlady et al. 1996, Teske, Liessem et al. 2018). To induce a breakdown of the mitochondrial inner transmembrane potential (i.e. sub-lethal mitochondrial stress reaction), the oligodendroglial cell line OLN93 was stimulated with $10 \mathrm{mM}$ sodium azide (SA) for $24 \mathrm{~h}$ as previously described by Teske et al. (Teske, Liessem et al. 2018). Afterwards, cells were kept in culture for additional $24 \mathrm{~h}$ to produce OCM (oligodendroglial cell conditioned medium). To confirm that the used SA concentration was not inducing immediate cell death, lactate dehydrogenase (LDH) cytotoxicity assay and cell titer blue viability assay were performed after $24 \mathrm{~h}$ of SA-treatment. Results are shown in figure 1A. LDH levels in the cell culture supernatants were significantly increased after SA treatment compared to vehicle, indicating cell death; LDH levels of lysis control was significantly increased compared to both treatment groups 
(left histogram in figure 1A). SA-induced LDH release was paralleled by a trend towards lower levels of metabolic activity in these cells (right histogram in figure 1A) however this difference was not statistically significant. Additionally, 10 mM SA-treated OLN93 cells did not show major morphological changes or loss of cell numbers at the microscopic level (figure 1B). Ddit3 and Atf3 are members of the integrated stress response which is closely connected to oxidative stress. Gene expression analysis of Ddit3 (Rutkowski, Arnold et al. 2006, Puthalakath, O'Reilly et al. 2007) and Atf3 (Edagawa, Kawauchi et al. 2014) was measured after the $24 \mathrm{~h}$ secretion phase via qPCR to confirm endoplasmic reticulum stress in SA-treated cells on the transcriptional level (figure 1C).

\section{Stressed oligodendroglial cells secrete various cytokines and chemokines}

In a next step, we aimed to analyze the gene expression of secreted molecules that oligodendroglial cells produce upon SA-induced mitochondrial stress. To get a first hint about the possible identity of such signaling molecules, we performed PCR arrays that screened for mRNA expression levels of 84 cytokines and chemokines with one sample $(n=1)$. Out of the 84 investigated genes, 13 were induced by at least 2 -fold when comparing the SA group with the vehicle group. Those 13 genes are displayed in figure 2A. IL6 and GDF15 were most robustly induced in stressed oligodendroglial cells compared to cells treated with vehicle. To confirm validity of the path finding gene array, we performed qPCR in independent samples from two additional experiments with each $\mathrm{n}=6$ for IL6, GDF15 and 3 randomly assigned genes (figure 2B). As indicated in figure 2B, IL6 gene expression and GDF15 gene expression were found to be induced > 12-fold in qPCR analysis in SA-treated OLN93 cells. Differences in between the gene expression measured in array analysis vs. qPCR are likely due to different evaluation strategies, i.e. different reference genes and subsequent software analysis and the measuring of only one sample in the PCR array. In comparison, genes for SPP1, LIF and CSF1 were induced 2.5- to 4-fold. In a next step, the relevance of the identified factors in vivo was investigated. Since short-term cuprizone intoxication mimics early lesion formation and induces stress in oligodendroglial cells, we re-evaluated gene array data from the CC of $2 \mathrm{~d}$ cuprizone-fed and control animals (Krauspe, Dreher et al. 2015). Results of this evaluation are shown in figure 2C. Out of the 13 investigated genes, 7 were significantly induced. Although GDF15 and CCL7 were highest induced in the tissue samples from cuprizone fed animals, oligodendroglial cells might be responsible - at least in part - for the increased IL6 expression in vivo. In a next step, we investigated whether oligodendroglial cells secrete IL6 on the protein level. Therefore, sandwich ELISA was performed using OCM from SA-treated and vehicle-treated oligodendroglial cells. Results are shown in figure $2 \mathrm{E}$ and demonstrate a 4-fold increase in IL6 levels upon SA-treatment. Our data show that stressed oligodendroglial cells express various signaling molecules that potentially activate microglia cells. To further investigate this hypothesis, the activation state of microglia cells was evaluated in OCM-stimulated BV2 microglia. Morphologically, no differences were found between cells growing in control medium (DMEM $0.5 \%$ ) and those cells grown in OCM-SA. Representative pictures after 6 hours incubation time are shown in figure 2D. Additionally performed arborization analysis and counting of bipolar cells did not reveal morphological changes in response to OCM-SA (supplementary figure E).

Expression levels of typical pro- and anti-inflammatory microglia markers were measured by means of qPCR $6 \mathrm{~h}$ after beginning of treatment (see supplementary figure A for experimental overview). Results of these experiments are shown in figure $2 \mathrm{~F}$. Gene expression of the anti-inflammatory marker arginase 1 was induced when BV2 microglia cells were treated with OCM from SA-treated oligodendroglial cells compared to OCM- 
vehicle-treated BV2 microglia. One factor that is known to be induced in microglia cells upon pro-inflammatory stimulation is NOS2 (Kempuraj, Thangavel et al. 2016). OCM-SA-treated BV2 microglia displayed an induced expression of NOS2 compared to control. Blocking of IL6 with anti-IL6 antibody only partly counteracted OCM-SA effects (figure $2 \mathrm{G}$ ) and none of the used concentrations of IL6 protein (10, 30 and $50 \mathrm{ng} / \mathrm{ml}$ ) was sufficient to show BV2 microglia responses with respect to the gene expression of both Nos2 and Arg1, indicating that other secreted molecules contribute to microglia activation in this scenario (supplementary figure F).

\section{Oligodendrocytes are a source of IL6 in vivo}

To investigate whether oligodendrocytes might be a relevant source of signaling molecules in vivo, we included short-term cuprizone-intoxicated mice (up to $4 \mathrm{~d}$ cuprizone) in the study. Since IL6 was highly induced in oligodendroglial cells in vitro, we focused on this molecule in this part of the study. Immunohistochemistry, qPCR and in situ hybridization were performed on brain slices of cuprizone-intoxicated animals. After $2 \mathrm{~d}$ of cuprizone intoxication, IBA-1 immunohistochemistry revealed that microglia display an activated cell morphology in the CC (i.e. less ramified, swollen somata) compared to control mice (figure 3A). Similar morphological changes as well as an increase in microglia cell numbers in early cuprizone-induced lesions have been published previously by our group after a 2 d exposure to cuprizone (Clarner, Janssen et al. 2015, Krauspe, Dreher et al. 2015). Re-evaluation via qPCR revealed that IL6 gene expression was increased about 5-fold in the $\mathrm{CC}$ after $2 \mathrm{~d}$ of cuprizone intoxication ((Krauspe, Dreher et al. 2015), figure 3B, $\mathrm{n} \geq 3$ ). This induction further increased up to 17-fold after $4 \mathrm{~d}$ of cuprizone intoxication. In situ hybridization showed an increase of IL6 mRNA signals in the CC of cuprizone-intoxicated animals compared to controls (figure $3 \mathrm{C}$, left panel). Double in situ hybridization (figure 3C, right panel) and validation by fluorescence double labeling of Olig2 and IL6 proteins (figure 3D) as well as double chromogen labeling of APC and IL6 proteins (figure 3E) revealed oligodendroglial cells as one source of IL6 at this early time point (see supplementary figure B for experimental overview). Although APC as well labels astrocytes and neurons in the brain, the double-positive cell in figure $3 \mathrm{E}$ resembles morphologically strongly an oligodendrocyte. Three cuprizone-fed animals were investigated and IL6/Olig2 and APC positive cells were found in the CC in all three animals. Since confocal Z-stack analysis was necessary to undoubtedly identify double-positive cells, no quantification of the number of these cells could be performed. Note that oligodendrocytes are not the sole source of IL6 but also other glial cells such as astrocytes express IL6 after 2 days of cuprizone feeding (see supplementary figure D). Tezuka and colleagues also identified astrocytes as a source of IL6 in this model (Tezuka, Tamura et al. 2013).

\section{Discussion}

The contribution of stressed oligodendrocytes to the formation of inflammatory CNS lesions is only incompletely understood. Here, we induced oligodendrocyte stress by using the mitochondrial inhibitor SA in vitro and cuprizone intoxication in vivo. In vitro, this treatment caused a selective increase in the oligodendroglial expression of a variety of immune-modulatory factors such as IL6, GDF15 and a number of chemokines. The expression of IL6 in the in vivo situation was explored by qPCR analysis, ELISA, in situ hybridization and immunohistological staining of tissue from short-term cuprizone-intoxicated mice. Fluorescence double labeling and in situ hybridization of OLIG2 and IL6 identified oligodendrocytes as possible source of this molecule in vivo (Ramesh, Benge et al. 2012). These results indicate that our in vitro data obtained 
from SA-treated oligodendroglial cells might be relevant for the in vivo situation. It has to be mentioned at this point, that oligodendrocytes are not the sole source of these molecules in vivo. With respect to IL6, astrocytes and microglia have been shown to be additional sources in cuprizone intoxication. We would like to point out

310 that due to the high number of possibly involved molecules and the highly complex interplay of different glia cells in the formation of early inflammatory lesions, knock-out mice deficient for single molecules would be of limited use to further investigate the role of oligodendrocytes in this scenario.

Regarding the role of IL6 in CNS inflammation and regeneration in general it has been shown that on one hand, it is neuroprotective via accelerating nerve regeneration following trauma or spinal cord injury (Hirota, Kiyama et al. 1996, Yang, Wen et al. 2012) and protects mice from demyelination in the cuprizone model by inducing a specific activation state in microglia (Petkovic, Campbell et al. 2017). On the other hand, IL6 supports chronic inflammatory processes in disorders such as Alzheimer's disease (Swardfager, Lanctot et al. 2010). In active demyelinating MS lesions, IL6 expression by astrocytes and macrophages is relevant for the preservation of oligodendrocytes (Schonrock, Gawlowski et al. 2000). IL6 signaling and mitochondrial functions are closely linked, since IL6 protects cells against a loss of mitochondrial complex IV after bacterial infection in mice (Maiti, Sharba et al. 2015). In the liver, IL6 is necessary for the repair of mitochondrial mutations caused by ethanol intoxication (Zhang, Tachibana et al. 2010). The physiological IL6 concentration in blood plasma samples from healthy humans is about $1-1.5 \mathrm{pg} / \mathrm{ml}$ whereas the concentration in inflammatory conditions is highly increased and might reach up to $1,000 \mathrm{pg} / \mathrm{ml}$ in sever inflammation (Damas, Ledoux et al. 1992, Seino, Ikeda et al. 1994, Ridker, Rifai et al. 2000). This is comparable to the concentrations we measured in the medium of stressed oligodendroglial cells (app. 800 pg/ml). Regarding the IL6 concentrations within the brain, both in healthy and inflamed tissue, only little is known. Therefore further studies will have to show the local IL6 concentrations and precise source within brain tissue in distinct pathologies. With respect to microglia cells, it has been shown that a concentration of $100 \mathrm{ng} / \mathrm{ml}$ does activate Nos 2 mRNA expression in BV2 microglia (Matsumoto, Dohgu et al. 2018). Furthermore, IL6 $(50 \mathrm{ng} / \mathrm{ml})$ increases the mitochondrial $\mathrm{Ca}^{2+}$ levels in a STAT3-dependent manner in $\mathrm{CD}^{+} \mathrm{T}$ cells (Yang, Lirussi et al. 2015). By using Luciferin-expressing mice, we recently demonstrated that cuprizone intoxication causes an early induction of Nrf2-ARE signaling within the brain (Draheim, Liessem et al. 2016). Since Nrf2 has been shown to regulate IL6 expression (Wruck, Streetz et al. 2011), the increase in oxidative stress and subsequent Nrf2-activation might be a possible mechanism by which IL6 expression is initially triggered in oligodendrocytes in this model. Further studies including Nrf2deficient mice will have to show the link between oxidative stress and Nrf2 activity on one hand and the expression of IL6 in oligodendrocytes on the other hand. Given this data, we consider this early IL6 expression by oligodendrocytes during preactive lesion formation as a potential first "call for help" by metabolically dysfunctional or oxidatively challenged oligodendrocytes.

Another member of the IL6 cytokine family that was induced upon SA-stimulation in this study is LIF, which similar to IL6 signals through the JAK/STAT pathway. It is required for the induction of inflammatory responses of microglia and astrocytes to brain damage (Holmberg and Patterson 2006). Furthermore, it has been shown that LIF plays a role in the initial infiltration of inflammatory cells into the CNS and in the neuronal response to brain injury (Sugiura, Lahav et al. 2000). Another highly induced molecule in our study was GDF15, also known as macrophage inhibitory cytokine-1. Bonaterra et al. showed that GDF15 is functionally linked to IL6 signaling since it regulates inflammatory IL6-dependent processes in vascular injury (Bonaterra, Zugel et al. 2012). A study on the tumorigenesis of prostate carcinoma indicated that the expression of GDF15 is upregulated by IL6 
(Tsui, Chang et al. 2012). Despite these links to IL6 signaling, GDF15 plays a major role in regulating inflammatory pathways in injured tissues and is involved in pathological processes such as cancer, cardiovascular disorders, ischemia and atherosclerosis (Schlittenhardt, Schmiedt et al. 2005, Kempf, Eden et al. 2006, Jiang, Wen et al. 2016).

A number of chemokines were induced in SA-treated OLN93 cells that are known to be involved in microglia activation, including CXCL1 and CCL5 (Škuljec, Sun et al. 2011). The cytokine-like glycoprotein SPP1, also known as osteopontin, was induced about 4-fold in stressed oligodendroglial cells. Osteopontin has been implicated in the pathogenesis of several autoimmune diseases such as rheumatoid arthritis, autoimmune hepatitis and MS (Chabas, Baranzini et al. 2001, Yumoto, Ishijima et al. 2002, Mochida, Yoshimoto et al. 2004). Furthermore, osteopontin activity is found in MS lesions (Chen, Chen et al. 2009). It has been shown that the treatment of mixed cortical cultures with osteopontin leads to a stimulation of myelin basic protein expression and the formation of myelin sheaths indicating a putative role in remyelination and recovery (Selvaraju, Bernasconi et al. 2004). CSF1, a macrophage colony-stimulating factor was induced 2.5-fold in SA-stressed oligodendroglial cells and is involved in the proliferation, differentiation, and chemotactic activity of monocytes and macrophages. Interestingly, the survival of adult murine microglia cells seems to be fully dependent upon CSF1 receptor signaling, since all microglia cells can be eliminated from the CNS through CSF1R inhibitor administration (Elmore, Najafi et al. 2014). All of the above mentioned signaling molecules might account - either alone or in combination - for the effects, we observed in OCM-treated microglia cells. Our data indicate that not a sole oligodendroglial cell-derived molecule but rather a combination of different factors account for the activation of microglia cells. In summary, our data supports the view that stressed oligodendrocytes have the potential to activate microglia cells through a specific cocktail of chemokines and cytokines such as IL6. Further studies will have to identify the temporal activation pattern of these signaling molecules, their cellular sources and impact on neuroinflammation.

\section{Acknowledgements}

374 The excellent support by Helga Helten, Petra Ibold and Uta Zahn is appreciated.We thank Prof. Dr.

375 ReinhardWindoffer and Dr. Volker Buck for their assistance with confocalmicroscopy and PD Dr. Claudia $376 \quad$ Krusche for technical support.

\section{Funding Information}

379 Grant sponsor: This study was funded by the START program of the medical faculty of the RWTH Aachen 380 University (M.S.).

\section{Compliance with ethical standards}

383 Conflict of Interest

384 The authors declare that they have no conflict of interest. 
A

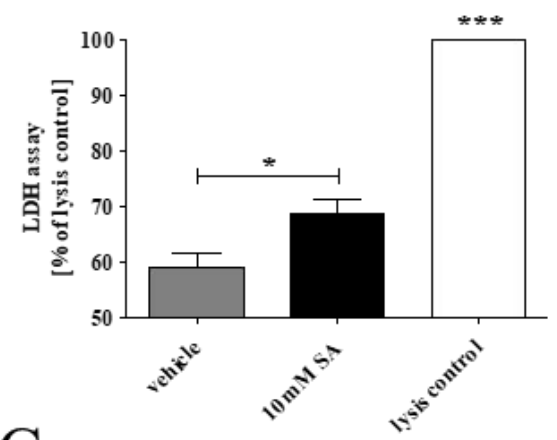

C Ddit3

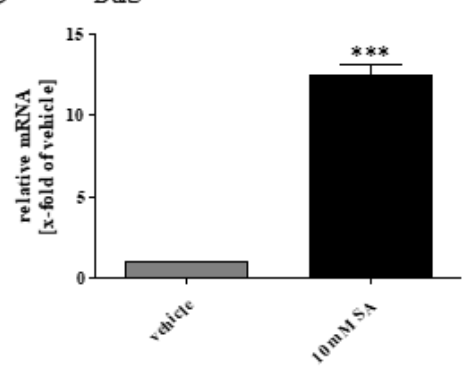

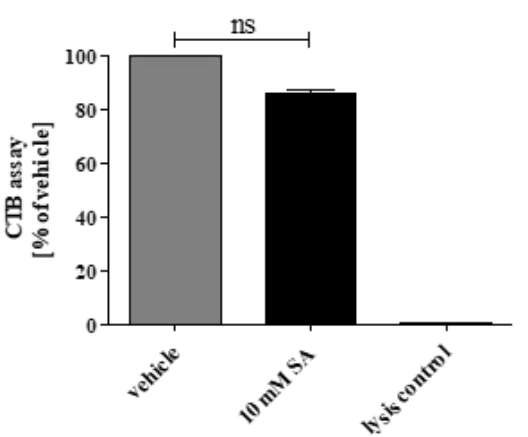

Atf3

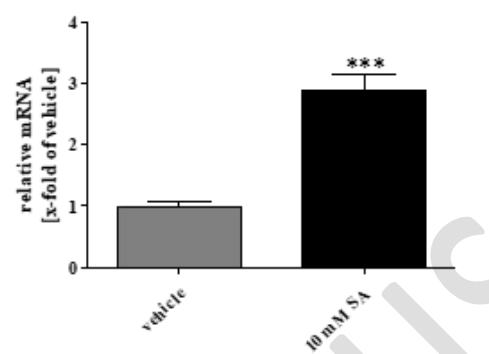

$\mathrm{B}$
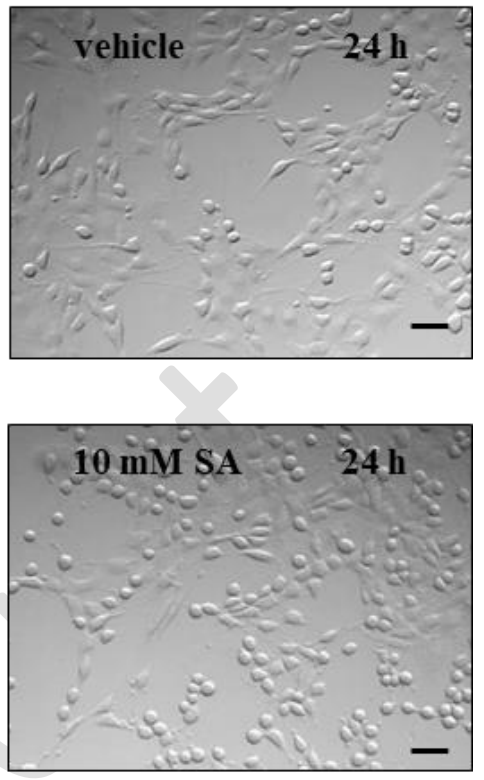

$386 \quad$ Figure 1

387 (A) Shows the cytotoxicity (left) assay normalized to the lysis control and cell viability (right) assay normalized

388 to the vehicle-treated cells of SA- and vehicle-treated OLN93 cells (eight culture wells, one experiment). (B)

389 Microscopic pictures using the FLoid ${ }^{\mathrm{TM}}$ Cell Imaging station (Thermo Fisher Scientific) of vehicle and SA-

390 treated oligodendroglial cells did not reveal obvious signs of cell loss or death (20X magnification). (C) Gene

391 expression analysis of Ddit3 and Atf3 (BoxCox-Y transformed) in vehicle- and SA-treated oligodendroglial cells

392 indicating metabolic stress (at least six culture wells, five independent experiments). ns = not significant, ${ }^{*} \mathrm{p}<0.05, * * \mathrm{p}<0.005, * * * \mathrm{p}<0.001$, vehicle $=$ up $\mathrm{H}_{2} \mathrm{O}$, scale bars $50 \mu \mathrm{m}$ 


\begin{tabular}{|c|c|c|c|c|c|c|c|c|c|c|c|c|c|}
\hline Gene Symbol & Il6 & Gdf15 & Cxcl3 & Cxcl1 & Ccl5 & Spp1 & Cxcl11 & Lif & Csf1 & Ccl7 & Ccl4 & Cxcl12 & I118 \\
\hline $\begin{array}{c}\text { Fold } \\
\text { regulation }\end{array}$ & 40.50 & 34.99 & 9.88 & 4.44 & 4.41 & 3.80 & 3.71 & 2.73 & 2.52 & 2.32 & 2.23 & 2.17 & 2.05 \\
\hline
\end{tabular}
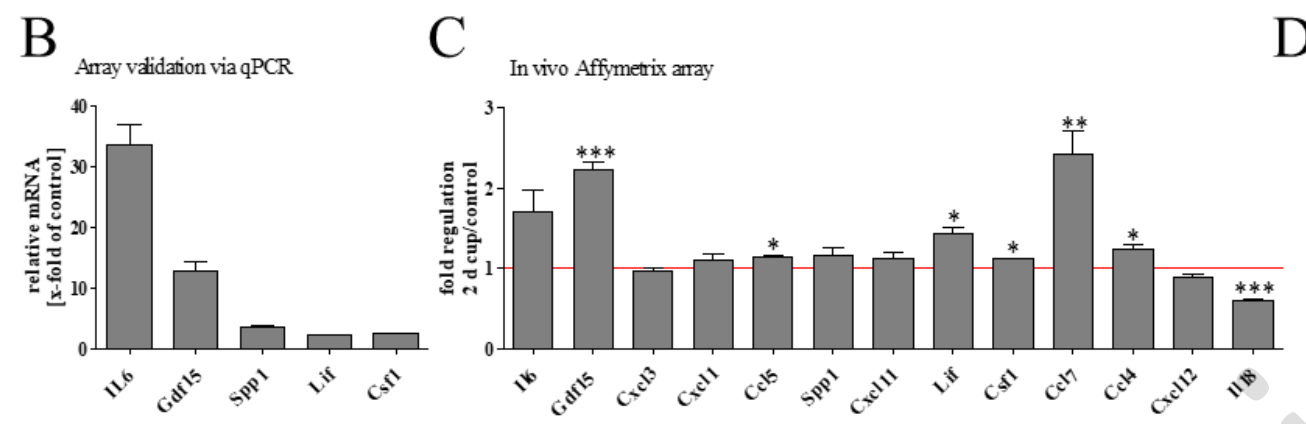

$\mathrm{D}$
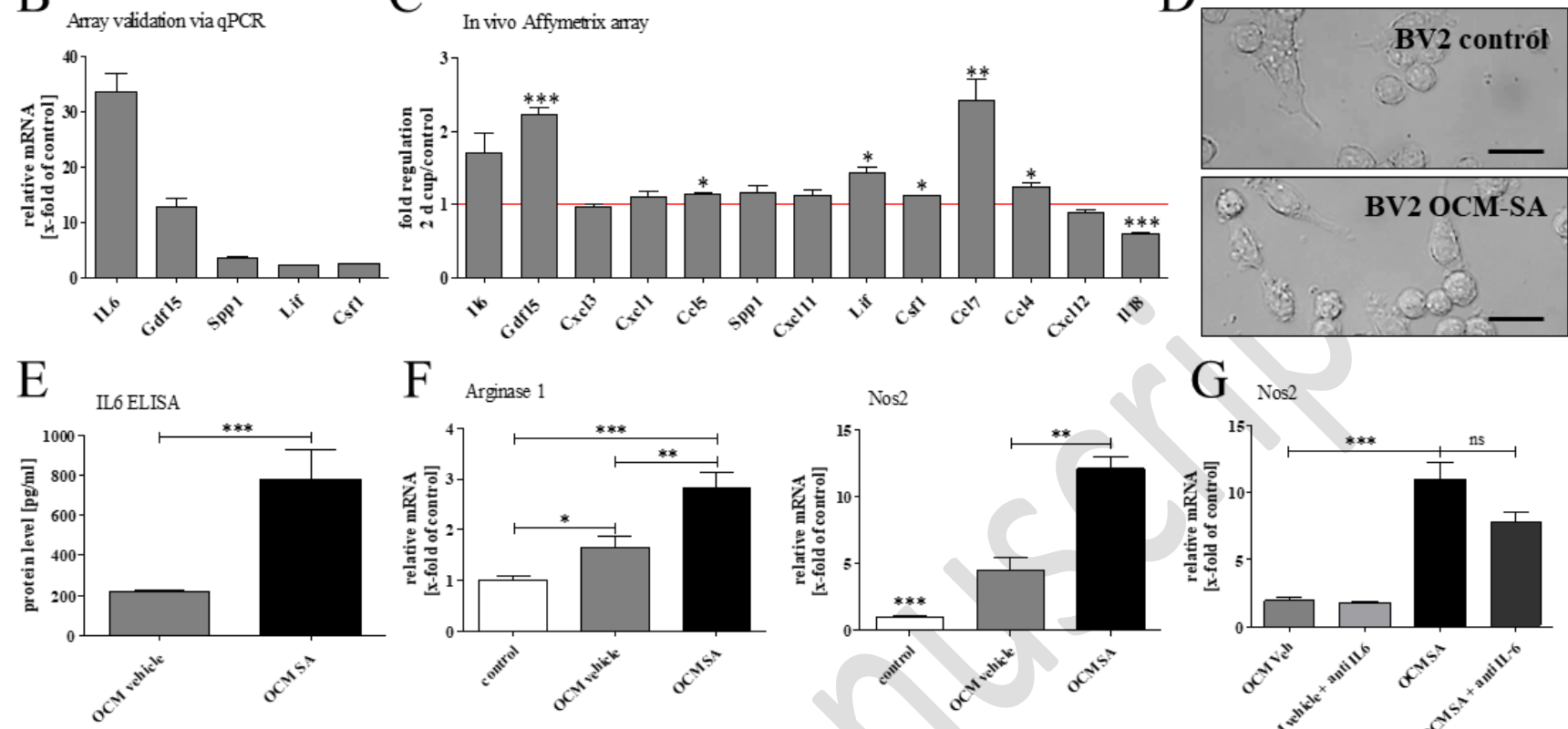

Figure 2

395 (A) Shows the fold difference of all chemokines and cytokines that were induced at least 2-fold in SA-treated OLN93 cells compared to control in the PCR array. (B) To validate the PCR array results, the gene expression was analyzed via qPCR on independent samples (at least six culture wells, two independent experiments). In (C) the re-evaluation of a gene array from the $\mathrm{CC}$ of $2 \mathrm{~d}$ cuprizone-intoxicated mice is shown. Data are displayed as fold induction of control. Note that a selective induction of the identified factors in oligodendroglial cells might be obscured due to the fact that this array measured expression in the whole tissue and not exclusively in oligodendrocytes (three animals per group, one experiment, see Krauspe, Dreher et al. 2015). (D) Shows representative pictures after 6 hours incubation time of BV2 microglia cells with OCM-SA and DMEM $0.5 \%$ (control). (E) IL6 protein levels increased up to 4-fold in stressed oligodendroglial cells versus unstressed oligodendroglial cells (BoxCox-Y transformed; six samples each group, two independent experiments). (F)

405 Shows the gene expression results of pro- and anti-inflammatory markers arginase 1 (BoxCox-Y transformed) and Nos2 of OCM-stimulated microglia cells (at least five culture wells, four independent experiments). (G) Induction of Nos2 expression by OCM was partly (not significant) counteracted by anti-IL6 antibody in the media. $\mathrm{ns}=$ not significant, ${ }^{*} \mathrm{p}<0.05,{ }^{* *} \mathrm{p}<0.005,{ }^{* * *} \mathrm{p}<0.001$, vehicle $=$ up $\mathrm{H}_{2} \mathrm{O}$, scale bars $30 \mu \mathrm{m}$ 


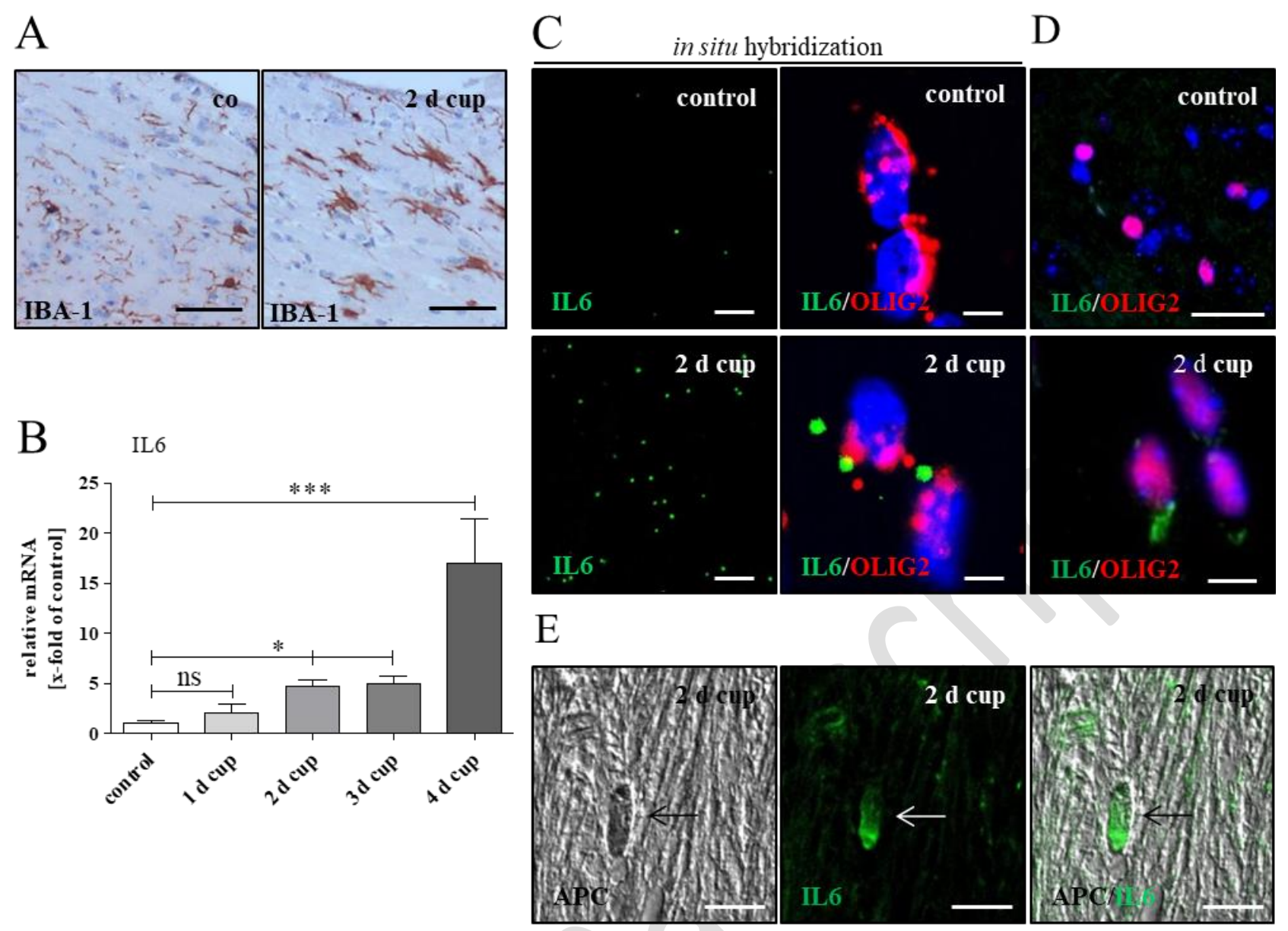

409 Figure 3

410 (A) IBA-1 $1^{+}$microglia cells display an activated morphology upon short-term cuprizone intoxication compared to 411 control mice (scale bars $50 \mu \mathrm{m}$ ). (B) IL6 gene expression was increased in the CC after 2, 3, and $4 \mathrm{~d}$ of 412 cuprizone intoxication compared to untreated animals (re-evaluation of cDNA of short-term cuprizone-fed mice; 413 BoxCox-Y transformed). (C) At $2 \mathrm{~d}$ of $0.25 \%$ cuprizone intoxication, the signal for IL6 mRNA was increased 414 compared to the control. In situ hybridization of OLIG2 and IL6 identified oligodendrocytes as source of IL6 415 production after short-term cuprizone intoxication (scale bars for IL6 $20 \mu \mathrm{m}$, for IL6/OLIG2 $5 \mu \mathrm{m}$ ), which was 416 further validated via fluorescence double labeling of OLIG2 and IL6 (scale bars for control $25 \mu \mathrm{m}$, for $2 \mathrm{~d}$ cup $41710 \mu \mathrm{m}$ ) (D) and double labeling of IL6 and APC (scale bars $10 \mu \mathrm{m}$ ) (E) (three animals per group, one experiment 418 for figure A - D). ns = not significant, *p $<0.05, * * \mathrm{p}<0.005, * * * \mathrm{p}<0.001$ 
A

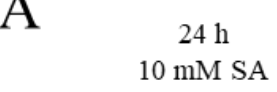

B

$19 \pm 2 \mathrm{~g}$ male

C57BL/6 mice
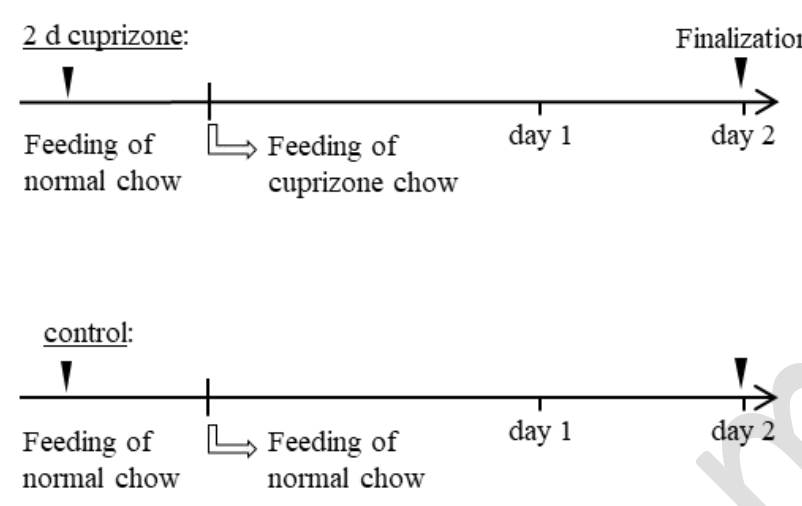

E
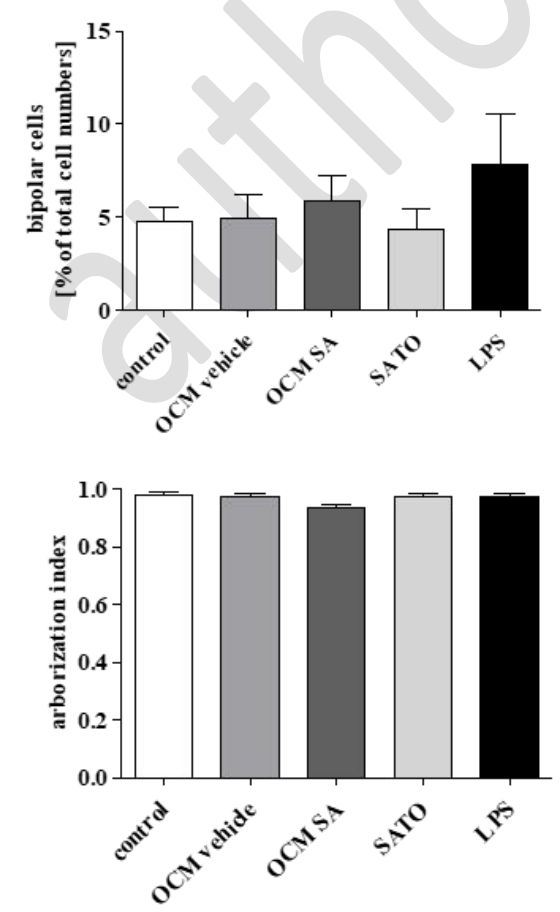

C

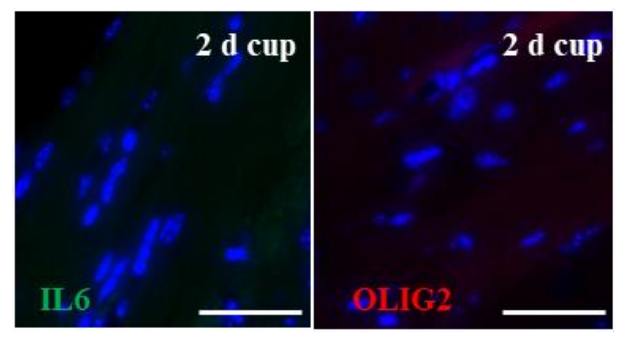

$\longleftrightarrow$ Gene expression analysis
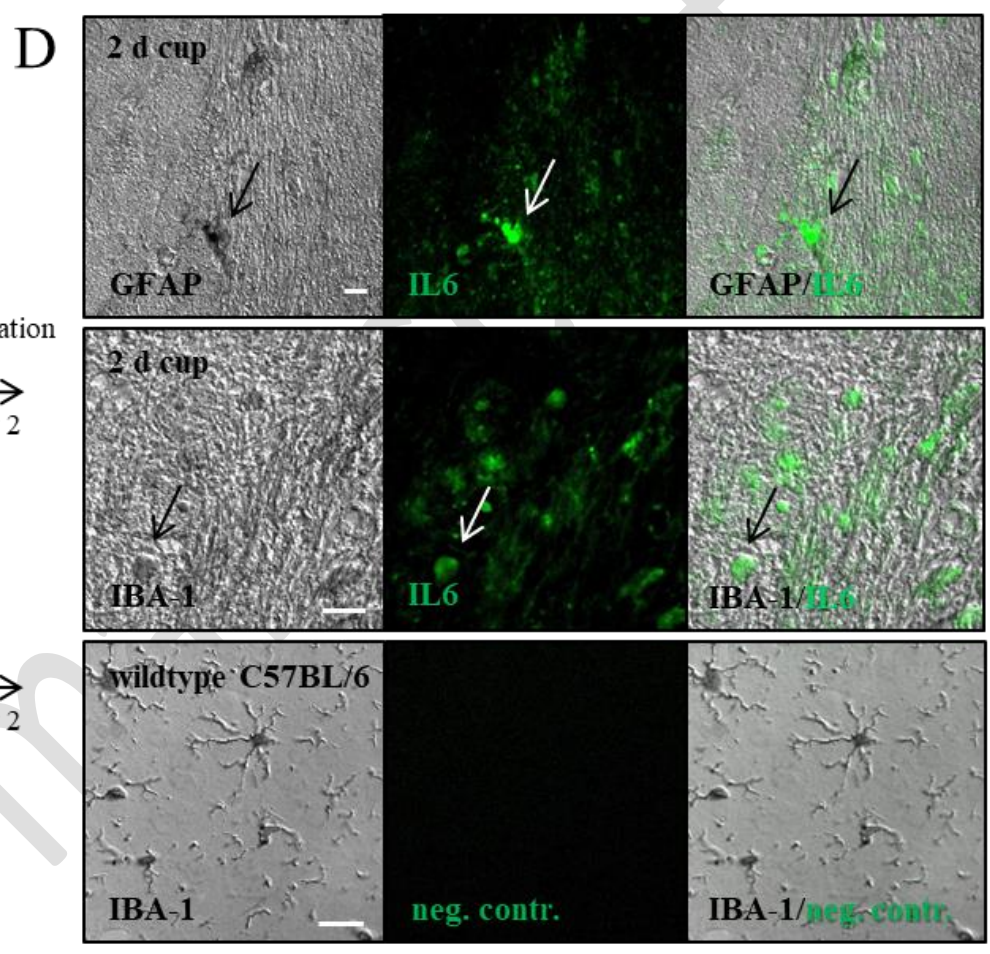

F
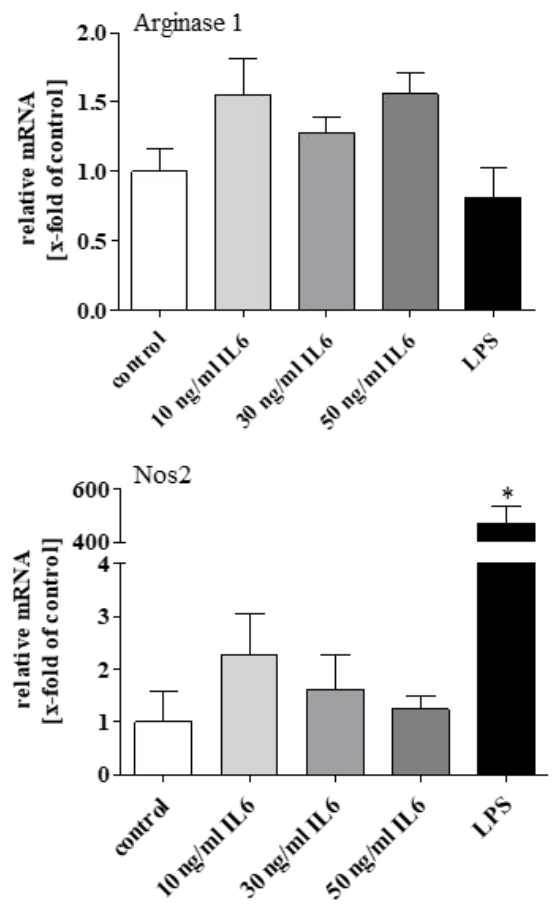
420 (A) Schematic illustration of the in vitro experimental setup for oligodendroglial cell stimulation and subsequent 421 microglia stimulation with OCM. Oligodendroglial cells (OLN93) were stressed with $10 \mathrm{mM}$ SA for $24 \mathrm{~h}$, 422 medium changed and incubated for $24 \mathrm{~h}$ with or without SA to produce OCM-vehicle and OCM-SA, 423 respectively. OCM was then used to stimulate microglia cells for $6 \mathrm{~h}$. (B) Time-line diagram of the $2 \mathrm{~d}$ cuprizone 424 feeding in vivo experiments. (C) Signal specificity was validated by incubating slices with the respective 425 secondary antibody without pre-incubation with the first antibody. Results for IL6 and OLIG2 negative controls 426 are shown. Note that no signal was found within the examined tissue regions for any secondary antibody (scale 427 bars $50 \mu \mathrm{m}$ ). Cross reactivity of secondary antibodies with each other or the false primary antibody was 428 additionally excluded (data not shown). (D) Double labeling of IL6 with GFAP and IBA-1 (scale bars $10 \mu \mathrm{m}$ ) 429 shows that also other glial cells than oligodendrocytes are possible sources of IL6 in $2 \mathrm{~d}$ cuprizone intoxication. 430 No signal was found in the wildtype negative control (lower row) (scale bars $20 \mu \mathrm{m}$ ). (E) No morphological 431 changes such as an increase in the number of bipolar cells or an increased arborization were found in OCM-SA432 stimulated compared to OCM-Veh-stimulated BV2 microglia cells. (F) Shows the gene expression results of 433 arginase 1 and Nos2 (BoxCox-Y transformed) of IL6-stimulated microglia cells (four culture wells, one 434 experiment). LPS stimulation served as a positive control for Nos2 induction. $* p<0.05$, vehicle $=$ up $\mathrm{H}_{2} \mathrm{O}$ 
Balabanov, R., K. Strand, R. Goswami, E. McMahon, W. Begolka, S. D. Miller and B. Popko (2007). "Interferon-gamma-oligodendrocyte interactions in the regulation of experimental autoimmune encephalomyelitis." J Neurosci 27(8): 2013-2024.

Barnett, M. H. and J. W. Prineas (2004). "Relapsing and remitting multiple sclerosis: pathology of the newly forming lesion." Ann Neurol 55(4): 458-468.

441

Bennett, M. C., G. W. Mlady, Y. H. Kwon and G. M. Rose (1996). "Chronic in vivo sodium azide infusion induces selective and stable inhibition of cytochrome c oxidase." J Neurochem 66(6): 2606-2611.

Blasi, E., R. Barluzzi, V. Bocchini, R. Mazzolla and F. Bistoni (1990). "Immortalization of murine microglial cells by a v-raf/v-myc carrying retrovirus." J Neuroimmunol 27(2-3): 229-237.

Bonaterra, G. A., S. Zugel, J. Thogersen, S. A. Walter, U. Haberkorn, J. Strelau and R. Kinscherf (2012). "Growth differentiation factor-15 deficiency inhibits atherosclerosis progression by regulating interleukin-6dependent inflammatory response to vascular injury." J Am Heart Assoc 1(6): e002550.

Cannella, B. and C. S. Raine (2004). "Multiple sclerosis: cytokine receptors on oligodendrocytes predict innate regulation." Ann Neurol 55(1): 46-57.

Chabas, D., S. E. Baranzini, D. Mitchell, C. C. Bernard, S. R. Rittling, D. T. Denhardt, R. A. Sobel, C. Lock, M. Karpuj, R. Pedotti, R. Heller, J. R. Oksenberg and L. Steinman (2001). "The influence of the proinflammatory cytokine, osteopontin, on autoimmune demyelinating disease." Science 294(5547): 1731-1735.

Chen, M., G. Chen, H. Nie, X. Zhang, X. Niu, Y. C. Zang, S. M. Skinner, J. Z. Zhang, J. M. Killian and J. Hong (2009). "Regulatory effects of IFN-beta on production of osteopontin and IL-17 by CD4+ T Cells in MS." Eur J Immunol 39(9): 2525-2536.

Clarner, T., F. Diederichs, K. Berger, B. Denecke, L. Gan, P. van der Valk, C. Beyer, S. Amor and M. Kipp (2012). "Myelin debris regulates inflammatory responses in an experimental demyelination animal model and multiple sclerosis lesions." Glia 60(10): 1468-1480.

Clarner, T., K. Janssen, L. Nellessen, M. Stangel, T. Skripuletz, B. Krauspe, F. M. Hess, B. Denecke, C. Beutner, B. Linnartz-Gerlach, H. Neumann, L. Vallieres, S. Amor, K. Ohl, K. Tenbrock, C. Beyer and M. Kipp (2015). "CXCL10 triggers early microglial activation in the cuprizone model." J Immunol 194(7): 3400-3413.

Damas, P., D. Ledoux, M. Nys, Y. Vrindts, D. De Groote, P. Franchimont and M. Lamy (1992). "Cytokine serum level during severe sepsis in human IL-6 as a marker of severity." Ann Surg 215(4): 356-362.

De Groot, C. J., E. Bergers, W. Kamphorst, R. Ravid, C. H. Polman, F. Barkhof and P. van der Valk (2001). "Post-mortem MRI-guided sampling of multiple sclerosis brain lesions: increased yield of active demyelinating and (p)reactive lesions." Brain 124(Pt 8): 1635-1645.

Draheim, T., A. Liessem, M. Scheld, F. Wilms, M. Weissflog, B. Denecke, T. W. Kensler, A. Zendedel, C. Beyer, M. Kipp, C. J. Wruck, A. Fragoulis and T. Clarner (2016). "Activation of the astrocytic Nrf2/ARE system ameliorates the formation of demyelinating lesions in a multiple sclerosis animal model." Glia 64(12): 22192230 .

Edagawa, M., J. Kawauchi, M. Hirata, H. Goshima, M. Inoue, T. Okamoto, A. Murakami, Y. Maehara and S. Kitajima (2014). "Role of activating transcription factor 3 (ATF3) in endoplasmic reticulum (ER) stress-induced sensitization of p53-deficient human colon cancer cells to tumor necrosis factor (TNF)-related apoptosisinducing ligand (TRAIL)-mediated apoptosis through up-regulation of death receptor 5 (DR5) by zerumbone and celecoxib." J Biol Chem 289(31): 21544-21561. 
Elmore, M. R., A. R. Najafi, M. A. Koike, N. N. Dagher, E. E. Spangenberg, R. A. Rice, M. Kitazawa, B. Matusow, H. Nguyen, B. L. West and K. N. Green (2014). "Colony-stimulating factor 1 receptor signaling is necessary for microglia viability, unmasking a microglia progenitor cell in the adult brain." Neuron 82(2): 380397.

Gay, F. W., T. J. Drye, G. W. Dick and M. M. Esiri (1997). "The application of multifactorial cluster analysis in the staging of plaques in early multiple sclerosis. Identification and characterization of the primary demyelinating lesion." Brain 120 ( Pt 8): 1461-1483.

Gehrmann, J., Y. Matsumoto and G. W. Kreutzberg (1995). "Microglia: intrinsic immuneffector cell of the brain." Brain Res Brain Res Rev 20(3): 269-287.

Hirota, H., H. Kiyama, T. Kishimoto and T. Taga (1996). "Accelerated Nerve Regeneration in Mice by upregulated expression of interleukin (IL) 6 and IL-6 receptor after trauma." J Exp Med 183(6): 2627-2634.

Hollensworth, S. B., C. Shen, J. E. Sim, D. R. Spitz, G. L. Wilson and S. P. LeDoux (2000). "Glial cell typespecific responses to menadione-induced oxidative stress." Free Radic Biol Med 28(8): 1161-1174.

Holmberg, K. H. and P. H. Patterson (2006). "Leukemia inhibitory factor is a key regulator of astrocytic, microglial and neuronal responses in a low-dose pilocarpine injury model." Brain Res 1075(1): 26-35.

Jiang, J., W. Wen and P. S. Sachdev (2016). "Macrophage inhibitory cytokine-1/growth differentiation factor 15 as a marker of cognitive ageing and dementia." Curr Opin Psychiatry 29(2): 181-186.

Kempf, T., M. Eden, J. Strelau, M. Naguib, C. Willenbockel, J. Tongers, J. Heineke, D. Kotlarz, J. Xu, J. D. Molkentin, H. W. Niessen, H. Drexler and K. C. Wollert (2006). "The transforming growth factor-beta superfamily member growth-differentiation factor-15 protects the heart from ischemia/reperfusion injury." Circ Res 98(3): 351-360.

Kempuraj, D., R. Thangavel, P. A. Natteru, G. P. Selvakumar, D. Saeed, H. Zahoor, S. Zaheer, S. S. Iyer and A. Zaheer (2016). "Neuroinflammation Induces Neurodegeneration." J Neurol Neurosurg Spine 1(1).

Krauspe, B. M., W. Dreher, C. Beyer, W. Baumgartner, B. Denecke, K. Janssen, C. D. Langhans, T. Clarner and M. Kipp (2015). "Short-term cuprizone feeding verifies N-acetylaspartate quantification as a marker of neurodegeneration." J Mol Neurosci 55(3): 733-748.

Kummer, J. A., R. Broekhuizen, H. Everett, L. Agostini, L. Kuijk, F. Martinon, R. van Bruggen and J. Tschopp (2007). "Inflammasome components NALP 1 and 3 show distinct but separate expression profiles in human tissues suggesting a site-specific role in the inflammatory response." J Histochem Cytochem 55(5): 443-452.

Linnane, A. W., S. Marzuki, T. Ozawa and M. Tanaka (1989). "Mitochondrial DNA mutations as an important contributor to ageing and degenerative diseases." Lancet 1(8639): 642-645.

Mahad, D., H. Lassmann and D. Turnbull (2008). "Review: Mitochondria and disease progression in multiple sclerosis." Neuropathol Appl Neurobiol 34(6): 577-589.

Maiti, A. K., S. Sharba, N. Navabi, H. Forsman, H. R. Fernandez and S. K. Lindén (2015). "IL-4 Protects the Mitochondria Against TNF $\alpha$ and IFN $\gamma$ Induced Insult During Clearance of Infection with Citrobacter rodentium and Escherichia coli." Scientific Reports 5: 15434.

Mao, P. and P. H. Reddy (2010). "Is multiple sclerosis a mitochondrial disease?" Biochimica et biophysica acta 1802(1): 66-79.

Marik, C., P. A. Felts, J. Bauer, H. Lassmann and K. J. Smith (2007). "Lesion genesis in a subset of patients with multiple sclerosis: a role for innate immunity?" Brain 130(Pt 11): 2800-2815. 

Kataoka (2018). "TNF-alpha-sensitive brain pericytes activate microglia by releasing IL-6 through cooperation between IkappaB-NFkappaB and JAK-STAT3 pathways." Brain Res 1692: 34-44.

Merabova, N., R. Kaminski, B. Krynska, S. Amini, K. Khalili and A. Darbinyan (2012). "JCV agnoproteininduced reduction in CXCL5/LIX secretion by oligodendrocytes is associated with activation of apoptotic signaling in neurons." J Cell Physiol 227(8): 3119-3127.

Mochida, S., T. Yoshimoto, S. Mimura, M. Inao, A. Matsui, A. Ohno, H. Koh, E. Saitoh, S. Nagoshi and K. Fujiwara (2004). "Transgenic mice expressing osteopontin in hepatocytes as a model of autoimmune hepatitis." Biochem Biophys Res Commun 317(1): 114-120.

Moyon, S., A. L. Dubessy, M. S. Aigrot, M. Trotter, J. K. Huang, L. Dauphinot, M. C. Potier, C. Kerninon, S. Melik Parsadaniantz, R. J. Franklin and C. Lubetzki (2015). "Demyelination causes adult CNS progenitors to revert to an immature state and express immune cues that support their migration." J Neurosci 35(1): 4-20.

Okamura, R. M., J. Lebkowski, M. Au, C. A. Priest, J. Denham and A. S. Majumdar (2007). "Immunological properties of human embryonic stem cell-derived oligodendrocyte progenitor cells." J Neuroimmunol 192(1-2): 134-144.

Perry, V. H., P. B. Andersson and S. Gordon (1993). "Macrophages and inflammation in the central nervous system." Trends Neurosci 16(7): 268-273.

Petkovic, F., I. L. Campbell, B. Gonzalez and B. Castellano (2017). "Reduced cuprizone-induced cerebellar demyelination in mice with astrocyte-targeted production of IL-6 is associated with chronically activated, but less responsive microglia." J Neuroimmunol 310: 97-102.

Puthalakath, H., L. A. O'Reilly, P. Gunn, L. Lee, P. N. Kelly, N. D. Huntington, P. D. Hughes, E. M. Michalak, J. McKimm-Breschkin, N. Motoyama, T. Gotoh, S. Akira, P. Bouillet and A. Strasser (2007). "ER stress triggers apoptosis by activating BH3-only protein Bim." Cell 129(7): 1337-1349.

Ramesh, G., S. Benge, B. Pahar and M. T. Philipp (2012). "A possible role for inflammation in mediating apoptosis of oligodendrocytes as induced by the Lyme disease spirochete Borrelia burgdorferi." $\underline{\mathbf{J}}$ Neuroinflammation 9: 72.

Richter-Landsberg, C. and M. Heinrich (1996). "OLN-93: a new permanent oligodendroglia cell line derived from primary rat brain glial cultures." J Neurosci Res 45(2): 161-173.

Ridker, P. M., N. Rifai, M. J. Stampfer and C. H. Hennekens (2000). "Plasma concentration of interleukin-6 and the risk of future myocardial infarction among apparently healthy men." Circulation 101(15): 1767-1772.

Ruther, B. J., M. Scheld, D. Dreymueller, T. Clarner, E. Kress, L. O. Brandenburg, T. Swartenbroekx, C. Hoornaert, P. Ponsaerts, P. Fallier-Becker, C. Beyer, S. O. Rohr, C. Schmitz, U. Chrzanowski, T. Hochstrasser, S. Nyamoya and M. Kipp (2017). "Combination of cuprizone and experimental autoimmune encephalomyelitis to study inflammatory brain lesion formation and progression." Glia 65(12): 1900-1913.

Rutkowski, D. T., S. M. Arnold, C. N. Miller, J. Wu, J. Li, K. M. Gunnison, K. Mori, A. A. Sadighi Akha, D. Raden and R. J. Kaufman (2006). "Adaptation to ER stress is mediated by differential stabilities of pro-survival and pro-apoptotic mRNAs and proteins." PLoS Biol 4(11): e374.

Scheld, M., B. J. Ruther, R. Grosse-Veldmann, K. Ohl, K. Tenbrock, D. Dreymuller, P. Fallier-Becker, A. Zendedel, C. Beyer, T. Clarner and M. Kipp (2016). "Neurodegeneration Triggers Peripheral Immune Cell Recruitment into the Forebrain." J Neurosci 36(4): 1410-1415.

Schlittenhardt, D., W. Schmiedt, G. A. Bonaterra, J. Metz and R. Kinscherf (2005). "Colocalization of oxidized low-density lipoprotein, caspase-3, cyclooxygenase-2, and macrophage migration inhibitory factor in arteriosclerotic human carotid arteries." Cell Tissue Res 322(3): 425-435. 
Schonrock, L. M., G. Gawlowski and W. Bruck (2000). "Interleukin-6 expression in human multiple sclerosis lesions." Neurosci Lett 294(1): 45-48.

Seino, Y., U. Ikeda, M. Ikeda, K. Yamamoto, Y. Misawa, T. Hasegawa, S. Kano and K. Shimada (1994). "Interleukin 6 gene transcripts are expressed in human atherosclerotic lesions." Cytokine 6(1): 87-91.

Selvaraju, R., L. Bernasconi, C. Losberger, P. Graber, L. Kadi, V. Avellana-Adalid, N. Picard-Riera, A. Baron Van Evercooren, R. Cirillo, M. Kosco-Vilbois, G. Feger, R. Papoian and U. Boschert (2004). "Osteopontin is upregulated during in vivo demyelination and remyelination and enhances myelin formation in vitro." Mol Cell Neurosci 25(4): 707-721.

Škuljec, J., H. Sun, R. Pul, K. Bénardais, D. Ragancokova, D. Moharregh-Khiabani, A. Kotsiari, C. Trebst and M. Stangel (2011). "CCL5 induces a pro-inflammatory profile in microglia in vitro." Cellular Immunology 270(2): 164-171.

Su, K., D. Bourdette and M. Forte (2013). "Mitochondrial dysfunction and neurodegeneration in multiple sclerosis." Front Physiol 4: 169.

Sugiura, S., R. Lahav, J. Han, S. Y. Kou, L. R. Banner, F. de Pablo and P. H. Patterson (2000). "Leukaemia inhibitory factor is required for normal inflammatory responses to injury in the peripheral and central nervous systems in vivo and is chemotactic for macrophages in vitro." Eur J Neurosci 12(2): 457-466.

Swardfager, W., K. Lanctot, L. Rothenburg, A. Wong, J. Cappell and N. Herrmann (2010). "A meta-analysis of cytokines in Alzheimer's disease." Biol Psychiatry 68(10): 930-941.

Teske, N., A. Liessem, F. Fischbach, T. Clarner, C. Beyer, C. Wruck, A. Fragoulis, S. C. Tauber, M. Victor and M. Kipp (2018). "Chemical hypoxia-induced integrated stress response activation in oligodendrocytes is mediated by the transcription factor nuclear factor (erythroid-derived 2)-like 2 (NRF2)." J Neurochem 144(3): 285-301.

Tezuka, T., M. Tamura, M. A. Kondo, M. Sakaue, K. Okada, K. Takemoto, A. Fukunari, K. Miwa, H. Ohzeki, S. Kano, H. Yasumatsu, A. Sawa and Y. Kajii (2013). "Cuprizone short-term exposure: astrocytic IL-6 activation and behavioral changes relevant to psychosis." Neurobiol Dis 59: 63-68.

Tsui, K. H., Y. L. Chang, T. H. Feng, L. C. Chung, T. Y. Lee, P. L. Chang and H. H. Juang (2012). "Growth differentiation factor-15 upregulates interleukin-6 to promote tumorigenesis of prostate carcinoma PC-3 cells." $\mathbf{J}$ Mol Endocrinol 49(2): 153-163.

Tzartos, J. S., M. A. Friese, M. J. Craner, J. Palace, J. Newcombe, M. M. Esiri and L. Fugger (2008). "Interleukin-17 production in central nervous system-infiltrating T cells and glial cells is associated with active disease in multiple sclerosis." Am J Pathol 172(1): 146-155.

van der Valk, P. and S. Amor (2009). "Preactive lesions in multiple sclerosis." Curr Opin Neurol 22(3): 207-213.

Wang, C. H., S. B. Wu, Y. T. Wu and Y. H. Wei (2013). "Oxidative stress response elicited by mitochondrial dysfunction: implication in the pathophysiology of aging." Exp Biol Med (Maywood) 238(5): 450-460.

Wruck, C. J., K. Streetz, G. Pavic, M. E. Gotz, M. Tohidnezhad, L. O. Brandenburg, D. Varoga, O. Eickelberg, T. Herdegen, C. Trautwein, K. Cha, Y. W. Kan and T. Pufe (2011). "Nrf2 induces interleukin-6 (IL-6) expression via an antioxidant response element within the IL-6 promoter." J Biol Chem 286(6): 4493-4499.

Wuerfel, J., J. Bellmann-Strobl, P. Brunecker, O. Aktas, H. McFarland, A. Villringer and F. Zipp (2004). "Changes in cerebral perfusion precede plaque formation in multiple sclerosis: a longitudinal perfusion MRI study." Brain 127(Pt 1): 111-119. 
600 cortical spinal tract injury by reactivating intrinsic growth program of neurons and enhancing synapse 601 formation." Exp Neurol 236(1): 19-27.

602 Yang, R., D. Lirussi, T. M. Thornton, D. M. Jelley-Gibbs, S. A. Diehl, L. K. Case, M. Madesh, D. J. Taatjes, C. 603 Teuscher, L. Haynes and M. Rincon (2015). "Mitochondrial $\mathrm{Ca}(2)(+)$ and membrane potential, an alternative 604 pathway for Interleukin 6 to regulate CD4 cell effector function." Elife 4.

605 Yumoto, K., M. Ishijima, S. R. Rittling, K. Tsuji, Y. Tsuchiya, S. Kon, A. Nifuji, T. Uede, D. T. Denhardt and 606 M. Noda (2002). "Osteopontin deficiency protects joints against destruction in anti-type II collagen antibody607 induced arthritis in mice." Proc Natl Acad Sci U S A 99(7): 4556-4561.

608 Zeis, T., A. Probst, A. J. Steck, C. Stadelmann, W. Bruck and N. Schaeren-Wiemers (2009). "Molecular changes 609 in white matter adjacent to an active demyelinating lesion in early multiple sclerosis." Brain Pathol 19(3): 459610466.

611 Zhang, X., S. Tachibana, H. Wang, M. Hisada, G. M. Williams, B. Gao and Z. Sun (2010). "Interleukin-6 is an 612 important mediator for mitochondrial DNA repair after alcoholic liver injury in mice." Hepatology 52(6): 21376132147. 